\title{
The effects of building design on hazard of first service in Norwegian dairy cows
}

\author{
A. D. Martin, ${ }^{1}$ C. Kielland, S. T. Nelson, and O. Østerås ${ }^{2}$ \\ Norwegian University of Life Sciences, Department of Production Animal Clinical Sciences, PO Box 8146 Dep., NO-0033 Oslo, Norway
}

\begin{abstract}
Reproductive inefficiency is one of the major production and economic constraints on modern dairy farms. The environment affects onset of ovarian activity in a cow postcalving and influences estrus behavior, which in turn affects a stockperson's ability to inseminate her at the correct time. This study used survival analysis to investigate effects of building design and animal factors on the postpartum hazard of first service (HFS) in freestall-housed Norwegian Red cows. The study was performed on 232 Norwegian dairy farms between 2004 and 2007. Data were obtained through on farm measurements and by accessing the Norwegian Dairy Herd Recording System. The final data set contained data on 38,436 calvings and 27,127 services. Univariate Cox proportional hazard analyses showed that herd size and milk yield were positively associated with HFS. Total free accessible area and free accessible area available per cow year were positively associated with the HFS, as was the number of freestalls available per cow. Cows housed on slatted floors had a lower HFS than those housed on solid floors. Conversely, cows housed on rubber floors had a higher HFS than cows on concrete floors. Dead-ending alleyways reduced the hazard of AI after calving. A multivariable Cox proportional hazards model, accounting for herd management by including a frailty term for herd, showed relationships between hazard of postpartum service and explanatory variables. Animals in herds with more than 50 cows had a higher HFS [hazard ratio $(\mathrm{HR})=3.0$ ] compared with those in smaller herds. The HFS was also higher $(\mathrm{HR}=4.3)$ if more than $8.8 \mathrm{~m}^{2}$ of space was available per cow year compared with herds in which animals had less space. The HFS after calving increased with parity (parity 2 $\mathrm{HR}=0.5$, parity $\geq 3 \mathrm{HR}=1.7$ ), and was reduced if a lactation began with dystocia $(\mathrm{HR}=0.82)$ or was a breed other than Norwegian Red $(\mathrm{HR}=0.2)$. The frailty
\end{abstract}

Received February 13, 2015.

Accepted August 1, 2015.

${ }^{1}$ Corresponding author: adam.martin@nmbu.no

${ }^{2}$ Current address: Norwegian Cattle Health Services and TINE Extension Services, 1431 Ås, Norway. term, herd, was large and highly significant indicating a significant proportion of the variation resides at herd level. The hazard of first insemination decreased with time for all predictive variables, except dystocia. This study shows that providing adequate environmental conditions for estrus behavior is imperative for reproductive efficiency and after herd management factors and time from calving have been accounted for. Thus, optimizing building design for reproductive efficiency is of significant importance when constructing new cattle housing.

Key words: reproduction, dairy cow, freestall, housing

\section{INTRODUCTION}

Reproductive efficiency is one of the most important factors affecting the productivity, profitability, and also the environmental impact of dairy farming (De Vries, 2006; Lucy, 2007; Garnsworthy, 2011). Despite its key role in milk production and pressure to improve productivity, dairy cow reproductive performance has declined over the past half century (Royal et al., 2000; Lucy, 2007). Although recently reproductive performance appears to have stabilized in many populations throughout the world (Philipsson, 2011). A wide array of factors have been implicated in this fertility decline; genetics, feeding, metabolic stress, concurrent disease, reduced estrus expression, and reduced identification of estrus behaviors have all been reported to cause reduced reproductive performance (Lucy, 2007; Dobson et al., 2008). However, on a worldwide basis, it is most probable that a combination of these factors have brought about the decline in dairy cow fertility (Lucy, 2007).

Norway is one of the few countries in the world in which phenotypic dairy cow reproductive performance has remained constant (Refsdal, 2007). The Norwegian Red breed accounts for approximately $95 \%$ of the Norwegian dairy population. Nonreturn to service rates have been included in the breeding index of the Norwegian Red with a relative weight of between 8 and 15\% since 1972 (Andersen-Ranberg et al., 2005b). More recently, the interval from calving to first service (CFS) has been included in the breed's total merit index (Andersen-Ranberg et al., 2005a; Geno, 2014). 
In large part, the stable reproductive performance of the Norwegian Red has been attributed to the breeding program (Andersen-Ranberg et al., 2005b; Garmo et al., 2009b). However, phenotypic performance is the result of a combination of genotype, environment, and genotype by environment interaction. Little attention has been given to the moderate yield of Norwegian cows (average yield in $2005=6,541 \mathrm{~kg}$ ), the relatively small herds they are kept in (average herd size in 2005 $=16.7$ cow years), the low levels of endemic infectious disease in Norway, or absence of routine use of timed AI breeding programs, all of which affect reproductive performance (Østerås et al., 2007; Refsdal, 2007). The absence of routine estrus synchronization and low levels of infectious disease (Østerås et al., 2007) make the study of environmental factors affecting reproduction less likely to be confounded by veterinary interventions in Norway than in other parts of the world.

Environmental influences are known to affect estrus behavior, the identification of which is a prerequisite for AI to be performed in the absence of timed AI programs (VanVliet and VanEerdenburg, 1996; Orihuela, 2000; Platz et al., 2008). Despite this, little work has been published on the effect of building design on traditional fertility measures. Although the importance of social interactions for reproduction has been discussed by several authors (Roelofs et al., 2005; Dobson et al., 2008; Sveberg et al., 2013), relatively few studies have been carried out to identify optimal herd size or space required per cow for displaying estrus behavior in freestall systems. Although the effect of herd size on reproductive performance is likely to be complex, one recent Norwegian study modeled 20 versus 50 cow herds and found the latter to have slightly improved reproductive performance (Simensen et al., 2010). In 2010, traditional tiestall housing was still the most common way to house Norwegian dairy cattle. However, legislation passed in Norway bans the use of cattle tiestalls from 2024 (Lovdata, 2013). Dairy producers with these facilities must build cubicle sheds or cease cattle production by 2024. Therefore, information about how building design influences cattle health and production is needed so that building designs can be optimized and returns from capital investments maximized. Our study aimed to investigate the effect of specific environmental factors, such as herd size, stocking density, floor type, and building layout, on CFS in Norwegian dairy cattle.

\section{MATERIALS AND METHODS}

\section{Farm Selection}

This study was part of a larger descriptive and crosssectional project on freestall housing in Norwegian dairy herds (Kielland et al., 2009; Naess and Boe, 2010). The Norwegian Dairy Herd Recording System (NDHRS, Ås, Norway), which in 2005 held records from 11,600 dairy farms, provided a list of 2,400 herds that were believed to have cattle housed in freestalls. A preliminary questionnaire was sent to these farms to gather background herd information and determine their willingness to participate in the study. Inclusion criteria for the study were farmers' willingness to participate, herd size $>20$ standardized cow years (based on the year 2005), barns built between 1995 and 2005, and the presence of freestalls. One cow-year was defined as the sum of the total of individual feed days for all cows in a herd over the course of a calendar year divided by 365. All farms that fulfilled the inclusion criteria were included in the study.

\section{Data Collection}

The herds were visited once during the indoor housing period between September 2006 and June 2007 by trained technicians; their training has previously been described (Naess and Boe, 2010). The technicians recorded type of flooring (in the alleys and feeding area), free accessible area (FAA; alleyways, freestalls, feeding areas), number of alleyways, number of dead-ending alleyways, and the total number of freestalls present on the farm for the adult cows (Naess and Boe, 2010). Herd level data were gathered from NDHRS database, including average herd milk yield per cow year (total milk delivered from the farm annually per cow years) and herd size (in cow years). Lactation level data were also extracted from this database (i.e., parity, breed, calving and service dates, as well as occurrence of dystocia).

\section{Statistical Analysis}

All available data concerning the lactations that occurred on the study farms in the period 2004 to 2007 were gathered in one database. The statistical program Stata 11 (Stata Corp., College Station, TX) was used for all analyses. This study was performed at the lactation level and cows could contribute more than one lactation to the study. The clustering effect of repeated lactations in individual cows was not accounted for in the statistical analyses. Cox regression analyses were performed and the outcome variable was CFS. The start day was the day of calving (DIM 1). The time to event was set as the time to first service after calving. Lactations which did not have any services were censored when an animal was culled or left the farm. On DIM 285, lactations were right censored if no record of service or AI had been recorded. The term stop day was used to describe right censoring. 


\section{Descriptive Statistics}

Continuous variables measured at the farm level were categorized to avoid unique values at farm level and thereby adjusting for herd-level factors more than once. The categories are shown in Table 1, which also gives a description of the explanatory variables (risk factors), their categorization, the number of lactations in each category, number of events, number of censored lactations, mean, and standard deviation of time to event. The association of the explanatory variables on time to event data were explored graphically using histograms, scatter plots, and Kaplan-Meier plots to understand the distribution of the data before survival analyses were performed.

\section{Survival Analysis}

Time to event data were analyzed using Cox proportional hazard modeling techniques. The start day, stop day, and definition of event have been previously described. The unit of study was lactation, individual cows were not limited to contributing just one lactation to the study. A shared frailty term for the variable farm was included in the model (Dohoo et al., 2009).

The explanatory variables were tested in univariate Cox proportional hazard models, a frailty term for the variable farm was included in the model to account for nonmeasured covariates found at the farm level (e.g., management). A crude hazard ratio for each explanatory variable was generated. Explanatory variables with a univariate $P$-value of less than 0.10 were included in a forward stepwise procedure to build a multivariable model.

After constructing a causal diagram to understand variables' influence on the outcome variable, a multivariable Cox proportional hazard model was built using a forward stepwise technique. Explanatory variables were added separately to the model and confounding could be observed as each variable was included. Potential confounding was defined as present if the coefficients of the variables already in the model altered by more than $20 \%$ when the new explanatory variable was included (Dohoo et al., 2009). Explanatory variables were retained in the model if the $P$-value for the likelihood ratio test was less than 0.05 . Two-way interactions between the explanatory variables in the final model were tested and an interaction term was retained if the interaction term's $P$-value was found to be significant.

The assumption of proportional hazards for each variable in the final model was explored using a proportional hazard test based on Schoenfeld residuals. For each of the variables that violated the assumption of proportional hazards, graphical evaluations of
Schoenfeld residual plots were explored to identify the possible type of time-varying effect of each variable. If the assumption of proportional hazards was found to be violated, an interaction term between the variable and time on a logarithmic scale was included in the model. Once the effect of time had been accounted for, the model was tested for overall fit, effect of outliers, and concordance to ensure the model was robust (Dohoo et al., 2009).

\section{Culling Data}

The method by which animals left the farm was initially categorized by 1 of 5 routes (slaughter, live sale, emergency slaughtered, died on farm, or other). The data were subsequently stratified according to whether the animal received a first service AI after calving or not, and the DIM before an animal left the herd (0-40, $41-80,81-120$, and $>120$ DIM). The chi-squared test was used to find differences in the reasons cows left the herd they calved in by the aforementioned time categories postpartum between the served and nonserved groups.

\section{RESULTS}

The data set consisted of 38,436 lactations which occurred in the period 2004 to 2007 on 232 farms. In 133 $(0.3 \%)$ lactations the cow died on the day of calving; these lactations were excluded from the data analysis. A service after calving was recorded in 27,127 lactations meaning that 11,309 lactations were censored. First service or culling from the herd was recorded for 37,124 cows before DIM 285. The total time at risk of first service was 3,261,279 cow days. Descriptive statistics on the study population may be obtained from Table 1 .

\section{Univariate Analysis}

The results of the univariate HFS analysis are shown in Table 1. The herd management variables, herd size and milk yield, were both positively associated with an hazard of CFS (i.e., larger herds and those on which the cows yielded more milk had a higher hazard of receiving a first service and therefore a lower CFS interval). When flooring was considered, total FAA, and FAA available per cow year (total FAA per cow years) were positively associated with the HFS, as was the number of freestalls available per cow year (total freestalls available for adults per cow years). Cows housed on slatted floors had a lower HFS than those housed on solid floors. Conversely those housed on rubber floors had a higher HFS than those housed on concrete floors. The presence of dead-ending alleyways in the freestall 
Table 1. Descriptive statistics and univariate Cox survival analysis of the predictor variables used to investigate the potential risk factors associated with time from calving to first service

\begin{tabular}{|c|c|c|c|c|c|c|c|c|c|c|c|}
\hline Variable & Group & $\begin{array}{l}\text { Number } \\
\text { of lactations }\end{array}$ & $\begin{array}{l}\text { Number } \\
\text { of events }\end{array}$ & $\begin{array}{l}\text { Mean } \\
\text { time to } \\
\text { event }\end{array}$ & $\mathrm{SD}$ & $\begin{array}{c}\text { Mean } \\
\text { time to } \\
\text { censuring }\end{array}$ & $\begin{array}{c}\text { SD, } \\
\text { time to } \\
\text { censuring }\end{array}$ & Estimate & $\mathrm{SE}$ & $\begin{array}{l}\text { Hazard } \\
\text { ratio }\end{array}$ & $P$-value \\
\hline \multicolumn{12}{|l|}{ Management } \\
\hline \multirow[t]{4}{*}{ Herd size (cow years) } & 1st quartile $(0.0-28.9)$ & 8,405 & 5,999 & 75.4 & 27.0 & 106.0 & 90.9 & Baseline & - & - & - \\
\hline & 2nd quartile $(29.0-40.6)$ & 8,189 & 5,734 & 75.8 & 30.1 & 114.0 & 97.6 & -0.039 & 0.018 & 0.962 & 0.035 \\
\hline & 3rd quartile $(40.7-53.3)$ & 8,678 & 6,110 & 74.5 & 27.8 & 108.7 & 95.1 & 0.007 & 0.018 & 1.008 & 0.671 \\
\hline & 4th quartile (53.4-80.5) & 8,609 & 6,154 & 70.9 & 26.7 & 103.2 & 90.6 & 0.106 & 0.018 & 1.112 & $<0.001$ \\
\hline \multirow{2}{*}{ Herd size (cow years) } & $<50$ & 23,844 & 16,806 & 75.1 & 27.9 & 111.3 & 95.2 & Baseline & - & - & - \\
\hline & $>50$ & 14,952 & 10,321 & 73.2 & 28.1 & 107.6 & 93.1 & 0.055 & 0.013 & 1.056 & $<0.001$ \\
\hline \multirow{4}{*}{$\begin{array}{l}\text { Average milk yield at herd level } \\
\text { (L) }\end{array}$} & 1st quartile $(0-6,500)$ & 8,652 & 6,163 & 75.2 & 28.5 & 117.6 & 96.1 & Baseline & - & - & - \\
\hline & 2nd quartile $(6.501-7,100)$ & 8,052 & 5,695 & 74.4 & 29.7 & 118.4 & 100.6 & 0.016 & 0.018 & 1.016 & 0.385 \\
\hline & 3rd quartile $(7,101-7,800)$ & 9,009 & 6,371 & 73.0 & 26.4 & 99.8 & 90.6 & 0.088 & 0.018 & 1.092 & $<0.001$ \\
\hline & 4th quartile $(7,801-10,000)$ & 8,164 & 5,768 & 73.7 & 27.2 & 96.7 & 85.1 & 0.089 & 0.018 & 1.092 & $<0.001$ \\
\hline \multirow{2}{*}{$\begin{array}{l}\text { Average milk yield at herdlevel } \\
\text { (L) }\end{array}$} & $0-7,100$ & 16,708 & 11,858 & 74.8 & 29.1 & 118.0 & 98.3 & Baseline & - & - & - \\
\hline & $7,101-10,000$ & 17,173 & 12,139 & 73.4 & 26.8 & 98.4 & 88.3 & 0.081 & 0.013 & 1.084 & $<0.001$ \\
\hline \multicolumn{12}{|l|}{ Housing } \\
\hline \multirow{4}{*}{$\begin{array}{l}\text { Free accessible area } \\
\left(\mathrm{m}^{2} / \text { cow year }\right)\end{array}$} & 1st quartile $(0.00-6.90)$ & 8,460 & 6,063 & 75.5 & 29.5 & 111.4 & 95.5 & Baseline & - & - & - \\
\hline & 2nd quartile (6.91-7.65) & 8,374 & 5,966 & 77.0 & 25.7 & 108.3 & 91.8 & -0.307 & 0.018 & 0.970 & 0.092 \\
\hline & 3rd quartile $(7.65-8.80)$ & 8,442 & 5,938 & 71.9 & 27.0 & 115.9 & 97.5 & 0.037 & 0.018 & 1.038 & 0.041 \\
\hline & 4th quartile $(8.81-18.5)$ & 8,605 & 6,030 & 71.9 & 29.0 & 97.1 & 89.0 & 0.103 & 0.018 & 1.109 & 0.000 \\
\hline \multirow{6}{*}{$\begin{array}{l}\text { Free accessible area } \\
\left(\mathrm{m}^{2} / \text { cow year }\right) \\
\text { Total floor space }\left(\mathrm{m}^{2}\right)\end{array}$} & $0.00-8.80$ & 25,276 & 17,967 & 74.9 & 27.6 & 111.9 & 95.0 & Baseline & - & - & - \\
\hline & $8.81-18.5$ & 8,605 & 6,030 & 71.9 & 29.0 & 97.1 & 89.0 & 0.101 & 0.015 & 1.107 & $<0.001$ \\
\hline & 1st quartile $(0-225)$ & 8,394 & 5,946 & 76.7 & 28.5 & 112.7 & 94.8 & Baseline & - & - & - \\
\hline & 2nd quartile (226-300) & 7,793 & 5,456 & 74.5 & 27.0 & 115.7 & 98.2 & 0.019 & 0.019 & 1.012 & 0.316 \\
\hline & 3rd quartile (301-450) & 9,613 & 6,836 & 73.2 & 26.9 & 104.4 & 90.5 & 0.096 & 0.018 & 1.101 & $<0.001$ \\
\hline & 4th quartile $(451-950)$ & 8,081 & 5,759 & 72.1 & 29.3 & 99.8 & 90.8 & 0.152 & 0.018 & 1.164 & $<0.001$ \\
\hline \multirow{2}{*}{ Total floor space $\left(\mathrm{m}^{2}\right)$} & $0-300$ & 16,187 & 11,402 & 75.6 & 27.8 & 114.1 & 96.5 & Baseline & - & - & - \\
\hline & $301-950$ & 17,694 & 12,595 & 72.7 & 28.1 & 102.3 & 90.7 & 0.112 & 0.013 & 1.119 & $<0.001$ \\
\hline \multirow{2}{*}{ Floor type } & Solid & 14,716 & 10,312 & 73.3 & 27.8 & 109.7 & 93.8 & Baseline & - & - & - \\
\hline & Slatted & 17,964 & 12,816 & 74.5 & 27.8 & 106.3 & 93.8 & 0.011 & 0.013 & 1.011 & 0.425 \\
\hline \multirow[t]{2}{*}{ Floor material } & Concrete & 30,106 & 21,307 & 74.5 & 28.0 & 108.3 & 94.6 & Baseline & - & - & - \\
\hline & Rubber & 2,312 & 1,649 & 67.3 & 25.5 & 100.9 & 85.0 & 0.170 & 0.026 & 1.185 & $<0.001$ \\
\hline \multirow[t]{2}{*}{ Dead-alleys } & Absent & 16.777 & 11,985 & 73.2 & 27.2 & 104.9 & 92.3 & Baseline & - & - & - \\
\hline & Present & 17,104 & 12,012 & 75.0 & 28.7 & 111.0 & 93.7 & -0.076 & 0.013 & 0.012 & $<0.001$ \\
\hline \multirow{3}{*}{ Cubicles per cow year } & $>1.1$ & 6,100 & 4,356 & 75.3 & 29.6 & 109.0 & 94.9 & Baseline & - & - & - \\
\hline & $1.0-1.1$ & 6.655 & 4,680 & 75.3 & 26.2 & 119.1 & 97.7 & -0.056 & 0.021 & 0.946 & 0.008 \\
\hline & $<1.0$ & 21,126 & 14,961 & 73.4 & 28.0 & 104.2 & 91.8 & -0.181 & 0.016 & 1.048 & 0.006 \\
\hline \multicolumn{12}{|l|}{ Animal } \\
\hline \multirow[t]{3}{*}{ Parity } & 1 & 14,386 & 10,839 & 74.6 & 28.6 & 95.5 & 91.0 & Baseline & - & - & - \\
\hline & 2 & 10,085 & 7,518 & 74.2 & 27.9 & 112.5 & 93.0 & -0.071 & 0.015 & 0.931 & $<0.001$ \\
\hline & $>3$ & 13.965 & 8,770 & 74.6 & 27.4 & 118.5 & 96.3 & -0.328 & 0.014 & 0.720 & $<0.001$ \\
\hline \multirow[t]{2}{*}{ Breed } & Other & 2,274 & 1,333 & 78.9 & 34.3 & 145.5 & 103.3 & Baseline & - & - & - \\
\hline & Norwegian Red & 36,162 & 25,794 & 74.2 & 27.6 & 106.7 & 92.9 & 0.437 & 0.028 & 1.548 & $<0.001$ \\
\hline \multirow{2}{*}{ Dystocia } & Absent & 35,003 & 24,984 & 74.2 & 27.8 & 111.3 & 94.1 & Baseline & - & - & - \\
\hline & Present & 2,870 & 1,820 & 76.3 & 30.0 & 99.2 & 96.3 & -0.135 & 0.023 & 0.874 & $<0.001$ \\
\hline
\end{tabular}


Table 2. Cox regression model with herd as shared frailty effect outcome variable time to first service

\begin{tabular}{|c|c|c|c|c|c|}
\hline Variable & Level & Estimate & $\mathrm{SE}$ & Hazard ratio & $P$-value \\
\hline \multicolumn{6}{|l|}{ Main } \\
\hline \multirow[t]{3}{*}{ Parity } & 1 & Baseline & - & - & - \\
\hline & 2 & 0.505 & 0.195 & 1.957 & 0.010 \\
\hline & $\geq 3$ & 1.714 & 0.182 & 5.552 & $<0.001$ \\
\hline \multirow[t]{2}{*}{ Dystocia } & $\overline{\mathrm{A}} \mathrm{bsent}$ & Baseline & - & - & - \\
\hline & Present & -0.199 & 0.025 & 0.820 & $<0.001$ \\
\hline \multirow[t]{2}{*}{ Breed } & Norwegian Red & Baseline & - & - & - \\
\hline & Other & -1.51 & 0.348 & 0.219 & $<0.001$ \\
\hline \multirow[t]{2}{*}{ Stocking density $\left(\mathrm{m}^{2} /\right.$ cow year $)$} & $\leq 8.8$ & Baseline & - & - & - \\
\hline & $>8.8$ & 1.110 & 0.188 & 3.035 & $<0.001$ \\
\hline \multirow[t]{2}{*}{ Herd size (cow years) } & $<50$ & Baseline & - & - & - \\
\hline & $\geq 50$ & 1.464 & 0.180 & 4.326 & $<0.001$ \\
\hline \multicolumn{6}{|l|}{ Time varying effect } \\
\hline \multirow[t]{3}{*}{ Parity } & 1 & Baseline & - & - & - \\
\hline & 2 & -0.144 & 0.457 & $-^{1}$ & 0.002 \\
\hline & $\geq 3$ & -0.492 & 0.042 & $\complement^{1}$ & $<0.001$ \\
\hline \multirow[t]{2}{*}{ Breed } & $\bar{O}$ ther & Baseline & - & - & - \\
\hline & Norwegian Red & -0.428 & 0.082 & $-^{1}$ & $<0.001$ \\
\hline \multirow[t]{2}{*}{ Stocking density ( $\mathrm{m}^{2} /$ cow year $)$} & $\leq 8.8$ & Baseline & - & - & - \\
\hline & $>8.8$ & -0.233 & 0.043 & $-^{1}$ & $<0.001$ \\
\hline \multirow[t]{2}{*}{ Herd size (cow years) } & $<50$ & Baseline & - & - & - \\
\hline & $\geq 50$ & -0.317 & 0.040 & $-^{1}$ & $<0.001$ \\
\hline $\begin{array}{l}\text { Frailty (herd) } \\
\text { Theta }\end{array}$ & & 0.121 & 0.013 & $<0.001^{2}$ & - \\
\hline
\end{tabular}

${ }^{1}$ Estimates of effect of factor varied over time- see Table 3 for estimates.

${ }^{2}$ Likelihood ratio test of frailty variance.

housing reduced the hazard of a cow being served for the first time. Parity and the occurrence of dystocia were both negatively associated with HFS. Norwegian Red cows had a higher HFS than those of a different breed.

\section{Multivariable Model}

The final multivariable model, calculated using data from 38,303 lactations, is shown in Table 2. It shows that the housing variables that significantly influenced the hazard of a cow receiving a first service were herd size and stocking density after adjustment for herd effects and several cow (parity, dystocia, and, breed) variables. The multivariable model also includes a frailty term (random effect) for the variable farm, which was large and highly significant, indicating that farm level factors that were not accounted for in the model had considerable effect on the HFS. Animals housed in herds with more than 50 cow years and animals that had more than $8.80 \mathrm{~m}^{2}$ of space per cow had an increased hazard of receiving service (i.e., a reduced CFS). The other variables which were shown to affect CFS in the final model were the animal-based risk factors: parity, breed, and incidence of dystocia. Increasing parity reduced the HFS as did the occurrence of dystocia at the start of a lactation. Breeds other than the Norwegian Red had a reduced HFS.

The effects of breed and parity were found to vary with time. The hazard of both older cows and cows from a breed other than Norwegian Red been inseminated for the first time after calving reduced as time from calving increased. The time-varying effects are shown with the multivariable model in Table 2.

\section{Culling Data}

A total of 22,486 animals left the herd they calved in during the study period. Of these, 11,182 had been served before they left the herd and the remaining 11,302 had not. The vast majority were slaughtered for human consumption $(\mathrm{n}=14,989)$. Data were missing for just over a quarter of the animals $(\mathrm{n}=5,951)$. Data on culling, on farm deaths, and live sales is presented in Table 3.

\section{DISCUSSION}

Our study shows that, despite inevitable management differences between farms, building design is likely to affect dairy cow reproductive performance. This is important because the dairy industry is in a period of considerable change, resulting in considerable investment in buildings, the greatest capital expense on a Norwegian dairy unit. Optimizing this investment is critical for animal welfare, efficient production, and profitability.

The survival regression techniques used in the current study preserved data that were censored, allowing for their inclusion in the analyses. In the current paper 


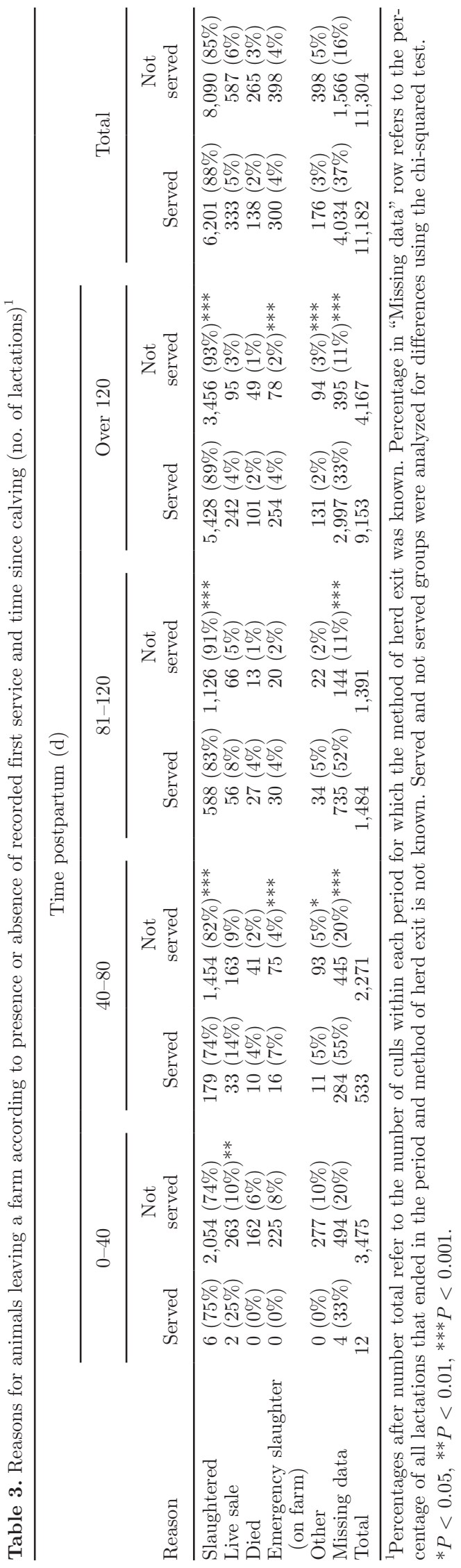

the outcome variable is time to CFS, and including time to censoring in cows that are not served improves the accuracy of the study. The outcome hazard ratio presents the effect of a unit change in the predictor on the frequency of the outcome (Dohoo et al., 2009). Hazard is defined as the risk of an animal experiencing the event of interest (e.g., first service) in the study period divided by the length of the interval (Dohoo et al., 2009).

\section{Multivariable Model}

When the multivariable Cox regression model was constructed only 2 herd-level housing factors remained in the model (stocking density and herd size). The model showed that increasing herd size and reducing stocking density increased the HFS. These findings are supported by previous work performed in Scandinavia, which found reproductive performance to be better in larger herds (Löf et al., 2007; Simensen et al., 2010)., although other studies have found that herd size does not affect fertility (Lane et al., 2013) or is actually deleterious to it (Lucy, 2001; Fahey et al., 2002). The apparent discrepancy between these studies is can be explained by differing herd sizes. In the study of Fahey et al. (2002), the smallest herd category contained up to 94 cows, whereas Lucy (2001) referred to herds over and under 200 cows. In the present study, over $60 \%$ of lactations occurred in herds containing less than 50 cow years. It is likely that increasing herd sizes at the level described in the current study are associated with improved management routines (Löf et al., 2007). Furthermore, it is likely that detection of estrus may be easier in the larger herds in our study, as increasing herd sizes increases the likelihood of transient sexually active groups forming, resulting in easier estrus detection, and thus a higher HFS (Hurnik et al., 1975; Sveberg et al., 2013).

Our study found that animals from herds with lower stocking densities had a higher hazard of first insemination. Some workers have reported that increasing stocking density will increase estrus behavior (De Silva et al., 1981; Orihuela, 2000); however, those studies have compared house- and pasture-based systems (De Silva et al., 1981; Phillips and Leaver, 1986; Orihuela, 2000). High stocking densities may act as a stimulus to estrus behavior; however, estrus behavior can be constrained when inadequate space for mounting and dismounting to occur safely is available (Vailes and Britt, 1990). The current study, when evaluated in the context of previous work (De Silva et al., 1981; Vailes and Britt, 1990; Orihuela, 2000), shows that there is likely to be an optimal stocking density for estrus detection. 
The multivariable model found certain animal level factors to be related to the HFS. Pluriparous cows had a lower HFS than primiparous cows, which appears to contradict a Norwegian population level study that found that pluriparous cows had fewer days to first insemination than primiparous cows (Refsdal, 2007). However, in the present study pluriparous cows did have a shorter CFS interval than primiparous animals. The difference in HFS in these groups exists because for management and economic reasons the censoring of pluriparous animals occurs later than primiparous animals. This increases their time at risk of insemination and decreases their HFS.

In the present study Norwegian Red cattle had a higher HFS than other breeds; however, the proportion other breeds is small, and this result should not be overinterpreted. The hazard of a Norwegian Red cow being inseminated for the first time reduced over time when compared with the other breeds in the present study. This may be because other breeds occur infrequently in the population, which increases their breeding value and thus reduces their culling risk.

Dystocia increases the risk of an animal contracting reproductive diseases (Beagley et al., 2010; Potter et al., 2010) and is associated with delayed onset of luteal activity, increased time until first service, increased serves per pregnancy, and increased days open (Fourichon et al., 2000; Dobson et al., 2001). Therefore, it is unsurprising that the present study showed that cows had a lower HFS if a lactation began with dystocia. Intuitively one would expect the effect of dystocia on HFS to decrease as time from calving increased, but this was not seen in the current study. Several possible explanations for this may exist; first, the length of time taken for the cows to recover and be ready for first service may mean animals no longer fit a farm's calving pattern and are culled. However, this is unlikely to be the reason, as year-round calving is the predominant calving pattern in Norway. Second, farmers may have decided to cull animals after dystocia without service. Third, dystocia is an infrequent occurrence in the Norwegian dairy population, with an incidence proportion of just 1.5\% (Østerås et al., 2007); therefore, the number of cases present in our study may be insufficient to provide the statistical power required to elucidate this complex relationship.

Herd was included in the final model as a frailty effect. The effect of herd was large and highly significant. This is unsurprising, as several factors that vary between farms and clearly influence CFS were not measured in the present study (e.g., type of service, voluntary waiting period, estrus detection protocols, and disease status). A model incorporating individual factors, factors at herd level, and a random effect (frail- ty) at herd level has some weaknesses. Relationships with the dichotomous outcome first service at cow level will be well represented for explanatory variables at cow level. For explanatory variables at herd level (e.g., floor type), the associations tend to be weaker in such a model than in reality because farm is represented in the equation more than once (i.e., both as a random effect and as an explanatory variable at herd level).

Some animals had more than one lactation included in the data set and, thus, the final model. This violates the principal of independence between recordings. However, a study measuring calving to conception intervals in dairy cattle has shown that more than $90 \%$ of the variation seen was found at the lactation level (Dohoo et al., 2001). This means the authors are confident about the reliability of the present study's findings, although the estimate of some individual features may be underestimated, or not appear in the final model, due to collinearity or the fact that herd effects are included twice in the multivariable model.

\section{Univariate Results}

Whereas the factors described in the multivariable model are those that have been shown to have the greatest influence on hazard of CFS, the initial univariate analyses also hold important information. The nature of cattle building design is such that selection of one feature often will closely correlate with others (e.g., an increased number of freestalls will likely increase the total floor space). These correlations are confounders and influence the effect of a predictor variable on the outcome variable in a multivariable model (Dohoo et al., 2009) such that univariate models are better suited for studying some of the relationships of the current study.

The univariate analyses revealed the importance of reducing social stressors in a cow's environment. These analyses indicate that increasing the number of freestalls available per cow, reducing stocking density, not having dead-ending alleys, and having a larger FAA to cattle all increased the HFS. These factors can reduce lying time (Caraviello et al., 2006; Fregonesi et al., 2007), increase aggressive interactions between cows for resources (Fregonesi et al., 2007), and reduce available feeding space (Schefers et al., 2010), all of which are known stressors. Stress negatively affects reproduction at a physiological level (Dobson and Smith, 2000). Building design and cattle housing affects metabolic status and disease; densely stocked cows generally have lower BCS, which are negatively correlated with reproductive performance (Roche et al., 2009). Housing design affects disease incidence, such as lameness, which can further affect estrus expression (Walker et 
al., 2010; Morris et al., 2011) and reproductive performance (Collick et al., 1989). Floor type affects the intensity of estrus expression (Vailes and Britt, 1990), which affects a stockperson's ability to detect estrus and perform AI (Roelofs et al., 2010). In the present study cows housed on concrete floors had a lower HFS than those housed on rubber floors, and cows housed on slatted floors had a lower HFS than those housed on solid floors. This is likely to be because cows housed on solid floors have lower levels of lameness and display estrus with a greater intensity than cows housed on slatted and concrete floors (Sogstad et al., 2006; Platz et al., 2008; Cook and Nordlund, 2009). The reason that more housing factors did not make it into the final model was likely due to collinearity when the multivariable model was constructed (Dohoo et al., 2009).

\section{Culling Data}

The data on why animals left the herd reveals some differences in whether animals were served or not. The most consistent difference was that unserved animals were more likely to go to slaughter than served animals. This is unsurprising, as several these animals would have been predetermined cull cows. Insemination in Norway costs approximately 500 Norwegian Krone (\$64), and therefore is unlikely to be performed in predetermined cull cow. Other cows sent to slaughter will have been culled because they have not displayed estrus or estrus has not been detected. This information is not available through the NDHRS register and, therefore, no judgment can be made on the proportion of planned culls that were deliberately not inseminated compared with those which were not inseminated for other reasons and culled. Predetermined cull cows represent a potential source of error in this study if culling distribution is not uniformly distributed across the studied variables. However, there is no reason to believe that management of cull cows is related to building design. Given this and the study population's size, we feel confident this error has not confounded the results of our study.

\section{CFS as a Measure of Reproductive Performance}

Days to first service is one of many measures used to assess the reproductive performance of dairy herds. Its use in scientific studies as a measure of reproductive performance can be criticized, as it may be influenced by several factors. These include physiological factors (e.g., time to onset of luteal activity after calving), managerial factors (e.g., length of voluntary waiting period), and environmental factors (e.g., ability of environment to allow expression of estrus); however, the multivariable model described in the current study includes a frailty term which accounts for the effect of herd.

Service records are believed to be accurate in Norway. Artificial insemination is almost exclusively performed by veterinary surgeons and technicians who receive payment after an insemination is registered in the central NDHRS database (Refsdal, 2007), from which the data used in the present study were extracted. The political framework present in Norway encourages uniform production by regulating price and feeding regimens (Garmo et al., 2009a). This, combined with a relatively early onset of luteal activity after calving (Garmo et al., 2009b), low incidence of abnormal patterns of ovarian cyclicity (Garmo et al., 2009a), low incidence of uterine disease (Østerås et al., 2007), and infrequent use of estrus synchronization programs (Kielland et al., 2009), mean that the use of CFS as a measure of reproductive performance is justifiable and reasonable.

\section{CONCLUSIONS}

This study shows that optimizing housing design will improve reproductive performance in dairy cows. In a multivariable model, increasing herd size and reducing stocking density increased the HFS after calving. The random effect of herd was large and significant. Univariate analyses show designing housing to reduce cow stress will increase the HFS. In conclusion, if dairy reproductive efficiency is to be optimal, careful attention should be paid to building design.

\section{ACKNOWLEDGMENTS}

The authors thank the farmers for their participation and the technicians Hans Kristian Hansen and Stine Kvivesen (both of Nord-Trøndelag University College) for their help and support during the trial. The access to data was given by the Norwegian Dairy Herd Recording System (Ås, Norway) and the Norwegian Cattle Health Services (Ås, Norway) in agreement number 3/2006.

\section{REFERENCES}

Andersen-Ranberg, I. M., B. Heringstad, D. Gianola, Y. M. Chang, and G. Klemetsdal. 2005a. Comparison between bivariate models for 56-day non-return and interval from calving to first insemination in Norwegian Red. J. Dairy Sci. 88:2190-2198.

Andersen-Ranberg, I. M., G. Klemetsdal, B. Heringstad, and T. Steine. 2005b. Heritabilities, genetic correlations, and genetic change for female fertility and protein yield in Norwegian dairy cattle. J. Dairy Sci. 88:348-355.

Beagley, J. C., K. J. Whitman, K. E. Baptiste, and J. Scherzer. 2010 Physiology and treatment of retained fetal membranes in cattle. J. Vet. Intern. Med. 24:261-268.

Caraviello, D. Z., K. A. Weigel, M. Craven, D. Gianola, N. B. Cook, K. V. Nordlund, P. M. Fricke, and M. C. Wiltbank. 2006. Analysis of reproductive performance of lactating cows on large dairy farms using machine learning algorithms. J. Dairy Sci. 89:4703-4722. 
Collick, D. W., W. R. Ward, and H. Dobson. 1989. Associations between types of lameness and fertility. Vet. Rec. 125:103-106.

Cook, N. B., and K. V. Nordlund. 2009. The influence of the environment on dairy cow behavior, claw health and herd lameness dynamics. Vet. J. 179:360-369.

De Silva, A. W. M. V., G. W. Anderson, F. C. Gwazdauskas, M. L. Mcgilliard, and J. A. Lineweaver. 1981. Interrelationships with estrous behavior and conception in dairy cattle. J. Dairy Sci. 64:2409-2418.

De Vries, A. 2006. Economic value of pregnancy in dairy cattle. J. Dairy Sci. 89:3876-3885.

Dobson, H., and R. F. Smith. 2000. What is stress, and how does it affect reproduction? Anim. Reprod. Sci. 60-61:743-752.

Dobson, H., J. E. Tebble, R. F. Smith, and W. R. Ward. 2001. Is stress really all that important? Theriogenology 55:65-73.

Dobson, H., S. L. Walker, M. J. Morris, J. E. Routly, and R. F. Smith. 2008. Why is it getting more difficult to successfully artificially inseminate dairy cows? Animal 2:1104-1111.

Dohoo, I., W. Martin, and H. Stryhn. 2009. Modelling survival data. Pages 467-528 in Veterinary Epidemiologic Research. 2nd ed. VER Inc., Charlottetown, Canada.

Dohoo, I. R., E. Tillard, H. Stryhn, and B. Faye. 2001. The use of multilevel models to evaluate sources of variation in reproductive performance in dairy cattle in Reunion Island. Prev. Vet. Med. 50:127-144.

Fahey, J., K. O'Sullivan, J. Crilly, and J. F. Mee. 2002. The effect of feeding and management practices on calving rate in dairy herds. Anim. Reprod. Sci. 74:133-150.

Fourichon, C., H. Seegers, and X. Malher. 2000. Effect of disease on reproduction in the dairy cow: A meta-analysis. Theriogenology 53:1729-1759.

Fregonesi, J. A., C. B. Tucker, and D. M. Weary. 2007. Overstocking reduces lying time in dairy cows. J. Dairy Sci. 90:3349-3354.

Garmo, R. T., A. D. Martin, E. Thuen, Ø. Havrevoll, H. Steinshamn, E. Prestløkken, Å. Randby, M. Eknæs, A. Waldmann, and O. Reksen. 2009a. Characterization of progesterone profiles in fall-calving Norwegian Red cows. J. Dairy Sci. 92:4919-4928.

Garmo, R. T., E. Ropstad, Ø. Havrevoll, E. Thuen, H. Steinshamn, A. Waldmann, and O. Reksen. 2009b. Commencement of luteal activity in three different selection lines for milk yield and fertility in Norwegian Red cows. J. Dairy Sci. 92:2159-2165.

Garnsworthy, P. 2011. The environmental impact of fertility in dairy cows. Pages 181-190 in Proc. Western Canada Dairy SeminarAdvances in Dairy Technology, Red Deer, Alberta. Accessed Sep. 8, 2015. http://www.wcds.ca/proc/2011/Manuscripts/Garnsworthy. pdf.

Geno. 2014. Total Merit Index. Vol. 2015. Accessed Sep. 9, 2015. http://www.genoglobal.com/Start/Norwegian-Red/aboutnorwegian-red/Norwegian-red-breeding-program/.

Hurnik, J. F., G. J. King, and H. A. Robertsen. 1975. Estrus and related behaviour in postpartum Holstein cows. Appl. Anim. Ethol. 2:55-68.

Kielland, C., L. E. Ruud, A. J. Zanella, and O. Østerås. 2009. Prevalence and risk factors for skin lesions on legs of dairy cattle housed in freestalls in Norway. J. Dairy Sci. 92:5487-5496.

Lane, E. A., M. A. Crowe, M. E. Beltman, and S. J. More. 2013. The influence of cow and management factors on reproductive performance of Irish seasonal calving dairy cows. Anim. Reprod. Sci. 141:34-41.

Löf, E., H. Gustafsson, and U. Emanuelson. 2007. Associations between herd characteristics and reproductive efficiency in dairy herds. J. Dairy Sci. 90:4897-4907.

Lovdata. 2013. Forskrift om hold av storfe. (Regulations on the keeping of cattle.) Accessed Mon. Day, Year. https://lovdata.no/ dokument/SF/forskrift/2004-04-22-665\#§14.

Lucy, M. C. 2001. Reproductive loss in high-producing dairy cattle: Where will it end? J. Dairy Sci. 84:1277-1293.

Lucy, M. C. 2007. Fertility in high-producing dairy cows: Reasons for decline and corrective strategies for sustainable improvement. Soc. Reprod. Fertil. Suppl. 64:237-254.
Morris, M. J., K. Kaneko, S. L. Walker, D. N. Jones, J. E. Routly, R. F. Smith, and H. Dobson. 2011. Influence of lameness on follicular growth, ovulation, reproductive hormone concentrations and estrus behavior in dairy cows. Theriogenology 76:658-668.

Naess, G., and K. E. Boe. 2010. Layouts and space allocation in Norwegian freestall dairy barns. Trans. ASABE 53:605-611.

Orihuela, A. 2000. Some factors affecting the behavioural manifestation of oestrus in cattle: A review. Appl. Anim. Behav. Sci. 70:1-16

Østerås, O., H. Solbu, A. O. Refsdal, T. Roalkvam, O. Filseth, and A. Minsaas. 2007. Results and evaluation of thirty years of health recordings in the Norwegian dairy cattle population. J. Dairy Sci. 90:4483-4497.

Philipsson, J. 2011. Interbull developments, global genetic trends and role in the era of genomics. Interbull Bull. 44:i-xiii.

Phillips, C. J. C., and J. D. Leaver. 1986. The effect of forage supplementation on the behavior of grazing dairy cows. Appl. Anim. Behav. Sci. 16:233-247.

Platz, S., F. Ahrens, J. Bendel, H. H. D. Meyer, and M. H. Erhard. 2008. What happens with cow behavior when replacing concrete slatted floor by rubber coating: A case study. J. Dairy Sci. 91:9991004

Potter, T. J., J. Guitian, J. Fishwick, P. J. Gordon, and I. M. Sheldon. 2010. Risk factors for clinical endometritis in postpartum dairy cattle. Theriogenology 74:127-134.

Refsdal, A. O. 2007. Reproductive performance of Norwegian cattle from 1985 to 2005: Trends and seasonality. Acta Vet. Scand. 49:5.

Roche, J. R., N. C. Friggens, J. K. Kay, M. W. Fisher, K. J. Stafford and D. P. Berry. 2009. Invited review: Body condition score and its association with dairy cow productivity, health, and welfare. J. Dairy Sci. 92:5769-5801

Roelofs, J., F. Lopez-Gatius, R. H. F. Hunter, F. J. C. M. van Eerdenburg, and C. Hanzen. 2010. When is a cow in estrus? Clinical and practical aspects. Theriogenology 74:327-344.

Roelofs, J. B., F. J. C. M. van Eerdenburg, N. M. Soede, and B. Kemp. 2005. Various behavioral signs of estrous and their relationship with time of ovulation in dairy cattle. Theriogenology 63:1366-1377.

Royal, M. D., A. O. Darwash, A. F. P. Flint, R. Webb, J. A. Wooliams, and G. E. Lamming. 2000. Declining fertility in dairy cattle: changes in traditional and endocrine parameters of fertility. Anim. Sci. 70:487-501.

Schefers, J. M., K. A. Weigel, C. L. Rawson, N. R. Zwald, and N. B. Cook. 2010. Management practices associated with conception rate and service rate of lactating Holstein cows in large, commercial dairy herds. J. Dairy Sci. 93:1459-1467.

Simensen, E., O. Østerås, K. E. Bøe, C. Kielland, L. E. Ruud, and G. Næss. 2010. Housing system and herd size interactions in Norwegian dairy herds: Associations with performance and disease incidence. Acta Vet. Scand. 52:14.

Sogstad, A. M., O. Østerås, and T. Fjeldaas. 2006. Bovine claw and limb disorders related to reproductive performance and production diseases. J. Dairy Sci. 89:2519-2528.

Sveberg, G., A. O. Refsdal, H. W. Erhard, E. Kommisrud, M. Aldrin, I. F. Tvete, F. Buckley, A. Waldmann, and E. Ropstad. 2013. Sexually active groups in cattle-a novel estrus sign. J. Dairy Sci. 96:4375-4386.

Vailes, L. D., and J. H. Britt. 1990. Influence of footing surface on mounting and other sexual behaviors of estrous Holstein cows. J. Anim. Sci. 68:2333-2339.

VanVliet, J. H., and F. J. C. M. VanEerdenburg. 1996. Sexual activities and oestrus detection in lactating Holstein cows. Appl. Anim. Behav. Sci. 50:57-69.

Walker, S. L., R. F. Smith, D. N. Jones, J. E. Routly, M. J. Morris, and H. Dobson. 2010. The effect of a chronic stressor, lameness, on detailed sexual behaviour and hormonal profiles in milk and plasma of dairy cattle. Reprod. Domest. Anim. 45:109-117. 